\title{
Research on Precision Strategy of Airline Customers under the Internet Environment
}

\author{
Yantao Wang ${ }^{1,}$, , Liang Zhang ${ }^{2, b}$ \\ ${ }^{1}$ Civil Aviation University of China, Tianjin, China \\ ${ }^{2}$ Airport Operation Management Department, Guangzhou Civil Aviation College, Guangzhou, China \\ a40435611@qq.com, b25267764@qq.com
}

Keywords: precision strategy, airline.

\begin{abstract}
This paper analyses the market environment of airlines' development, the SWOT analysis method is used to analyze the airlines' advantage, disadvantages, opportunities, threats, the development SWOT analysis diagram is constructed, the precision strategies of airline customers under the Internet environment are proposed, it provides the basis and references for the accurate positioning of the airlines' Internet network marketing, which is conducive to improve the economic benefits of the airlines.
\end{abstract}

\section{Analysis of Market Environment for Airlines' Development}

(1) Enterprise environment analysis

1. Political elements

At present, China's domestic political situation is stable; a good political environment is conducive to the airlines' development. At the same time, the establishment of aviation administration policy also provides convenience and help for the airlines' development. Our country attaches particular importance to safety, especially in air transport; there are strict legal norms in China. All the airlines put the safety problems first and strictly guarantee the flight safety.

2. Economic elements

Because China plays an important role in the current world economic diversified development, which cause economic environment of China's aviation development to maintain stable, and continue to develop toward a stable trend, there will be no huge rise or drop fluctuation for the time being. In addition, China's overall economy has been greatly improved relative to the past, and business development has led to the improvement of the time and cost requirements for business people, the aviation is undoubtedly their first choice.

3. Social elements

The country pays constant attention to the China' traditional culture, especially the Mid-autumn Festival and Tomb-Sweeping Day are determined as the national holiday, this reason causes the passenger flow to increase [1]. At the same time, due to the improvement of people's living standards at this stage, air fares are more discounted. On some holidays, especially during the Spring Festival, people choose planes more. At the same time, the development of China's tourism has led to the development of transportation industry as well. For people who want to enjoy life, comfortable aviation is undoubtedly their first choice.

(2) Analysis of industry competition environment

1. The domestic competition environment is fierce

Although China has a large population, the proportion of aviation consumption number is still relatively small due to economic development. In addition, even if there are few domestic airlines, the existing market share is already full. Each airline has its own unique operation way, and air route network with its own advantageous, and there are no obvious competitive advantages among airlines. At present, a lot of local airlines have begun to buy main line plane and participate in the business of gold main line, some companies apply the advice to run international local air lines, cause the transport capacity distribution to be imbalanced. The enhancement of competitiveness and many 
market investments directly lead to the decline of the whole industry performance and the occurrence of adverse price competition.

\section{Analysis of consumers}

The size of amount purchased of buyers: the passengers purchase tickets, one is that a single person buy a single ticket and another one is group ticket, The more the number of purchases, airlines are more willing to offer low prices, but it cannot be higher than team seat number specified by the airlines, otherwise buyers are unable to get the lowest price ticket; purchase ability and age structure: it can be concluded from spending power observation of our country passengers at present, The young people who get on plane predominate, there are more young passengers in the eastern and southern parts of China, there are more adult tourists in the western region, travel and business are the main purposes of trip.

\section{Analysis of potential entrants}

Because of the cost demand, economy scale, product difference, good distribution channels, experience and stagnation problems exist in air transport industry. Therefore, there is still some resistance for potential entrants to enter the aviation field, because entry threshold of the air transport industry is higher than other industries, and the exit threshold is also high, the overall revenue of the civil aviation industry is not high, so that there is an industry loss phenomenon. Therefore, the civil aviation bureau is always strictly control the enterprises which want to enter the civil aviation market, reduce the potential threat of new entrants. The establishment of bilateral aviation agreements makes the competition rate of China's aviation international market reduced, and sets up entry barriers, but the emergence of aviation alliance causes some airlines that do not directly enter the Chinese market indirectly involve in the competition.

\section{Analysis of alternatives}

There are train, ship, automobile and high-speed train four kinds of transportation means replace plane. Under the certain condition of people's demand, the share of the four vehicles will change with the product price, supply level and quality change. Today, transportation is developed, the fast and good service characteristics of air transportation are gradually replaced by high-speed train and tour bus. Country in order to develop the economy and increase domestic demand, by extending the highway mileage, enhances the railway transportation level and operation environment, so, investments in the infrastructure construction of transportation industry are mainly used on roads and railways. The productivity and consumer market are rapidly formed. The alternatives have strong market competitiveness.

\section{SWOT Analysis of Airlines' Development}

(1) Advantages of airlines

At present, the domestic airlines after many years of development, through reform and reorganization, attach importance to management, most enterprises have good operation condition and better growth space, the potential for future development is enormous; airlines lay emphasis on improving technical skills, pay attention to brand image shaping, provide passengers with "reliable, punctual, convenient" and "standardized and personalized organic integration" service, promote the image in the mind of passengers; various airlines pay attention to the rationalized construction of the fleet scale, the type is complete, the fleet scale is perfect; the airlines emphasize to the infrastructure construction, can adjust the operation amount in time, so that the operation can be carried out smoothly.

(2) Disadvantages of the airlines

In recent years, although the development pace of domestic airlines is rapid, but most airlines reach a certain scale, strategic development especially development is slow in the merger process, which affects the overall development pace of the airlines; some airlines is not enough for unique talents reserve of relevant professional departments, the enterprises' fleet resources and financial capability are insufficient, the asset degree limit the companies to expand the scale, it is difficult to rise to a new height; network development, the network precision development is not enough, there 
are no effective data analysis, targeted marketing and promotion, corresponding marketing strategies for the large customer group of online ticketing.

(3) Opportunities of airlines

In recent years, China's economic development is steady and order. Economic development has laid the foundation for the economic basis for development of aviation companies, technological progress has enabled aircraft manufacturers to lower prices and eased the economic pressure on airlines to expand fleet scale; the state has introduced a series of policies to promote development of civil aviation and provide convenience for the development of the airlines.

(4) Threat of airlines

With the continuous development of the civil aviation industry reform in China, the market competition of the civil aviation become even more violent, and the competition for ticket price is even fiercer, the overall development of the global economic environment still has considerable problems, the difficulty extent of finance for airlines has increased. The pessimism of the economic situation makes the positioning of the airlines inaccurate, which limit the development of the company; the price of the international crude oil market frequently fluctuates, aviation oil prices limit the cost control of airlines; and aviation dangerous events from time to time affect the psychology to consumers to choose transportation methods.

Based on the above analysis, this paper analyzes the current development status of airlines with the SWOT method, and forms the SWOT analysis diagram of airlines' development, and The SWOT strategic diagram of airlines' development as shown in Table 1and Table.2.

Table 1. developed SWOT analysis diagram of airlines

\begin{tabular}{|c|c|}
\hline $\begin{array}{c}\text { S superiority } \\
\text { good business situation and growth space of enterprises } \\
\text { technical skills improve } \\
\text { reasonable personnel structure } \\
\text { complete type and perfect fleet scale }\end{array}$ & $\begin{array}{l}\text { W weakness } \\
\text { slow development of the company's strategy } \\
\text { unique talent pool of relevant professional departments are not enough } \\
\text { network precision development is not enough } \\
\text { enterprise fleet resources and financial ability are not enough }\end{array}$ \\
\hline $\begin{array}{c}\text { O opportunity } \\
\text { economic development } \\
\text { state policy support } \\
\text { development potential is great } \\
\text { consumers' purchasing power improve }\end{array}$ & $\begin{array}{c}\text { T threat } \\
\text { aviation oil price } \\
\text { fierce market competition } \\
\text { financial crisis } \\
\text { aviation safety incidents } \\
\text { alternatives increase }\end{array}$ \\
\hline
\end{tabular}

Table 2. developed SWOT strategic diagram of airlines

\begin{tabular}{|c|c|}
\hline $\begin{array}{l}\text { S-O strategy } \\
\text { open up the characteristic products of the airlines to } \\
\text { meet the different needs of the consumers } \\
\text { further expand the scale of the company and improve } \\
\text { the level of development }\end{array}$ & $\begin{array}{l}\text { W-O strategy } \\
\text { strengthen the training of professional talents and improve the unique talent } \\
\text { pool in the professional department } \\
\text { make full use of the development of the market economy and the support of the } \\
\text { national policy to speed up the development strategy pace of the airlines } \\
\text { carry out accurate network marketing, expand market share and consumers }\end{array}$ \\
\hline $\begin{array}{l}\text { S-T strategy } \\
\text { Strengthen the technical skills of the company, save } \\
\text { the cost and improve the safety performance } \\
\text { guarantee the company's fund system and strengthen } \\
\text { the ability to avoid risk } \\
\text { set up the brand image of the enterprise and } \\
\text { strengthen the word of mouth marketing }\end{array}$ & $\begin{array}{l}\text { W-T strategy } \\
\text { speed up the strategic pace and improve the ability to avoid risk } \\
\text { expand the scope of Internet marketing, reduce the cost of the company and } \\
\text { improve the market share } \\
\text { expand finance channels and raise finance capacity }\end{array}$ \\
\hline
\end{tabular}

\section{The Precision Strategy of Airline Customers under the Internet Environment}

According to the analysis SWOT, combined with the current Internet development trend of our country, the airlines can reduce costs and improve the competitiveness through network marketing, promote the establishment of airlines' brand image, the precision network marketing can promote the airlines better expand the network market share, formulate personalized requirements for customers., strengthen word-of-mouth publicity effect, accurate network marketing first need to carry out the 
customers' market positioning, and then make the network precision marketing strategy in accordance with market positioning results, specific methods are as follows:

(1) Passengers who are 17- 28 years old and for travel purposes

The airlines can improve the difference price level for these part passengers and optimize the different pricing methods. Improve the market share and ensure the enterprise' profit as far as possible. We can adopt a low-price strategy for these passengers, the marketing are carried out through reduce costs and the price, we cannot provide food and reduce the extra service to reduce costs for this part of passengers in the flight process.

This part of the visitors tend to be younger in network promotion, They are sensitive to network information and have strong communication, airlines can take its official website and Sina micro-blog as the new news release platform, such as air line arrangement, airline ticket sales information publish and so on, grasp the construction of social media websites, the airlines' language expression too the official, serious and stiff in Sina micro-blog, lack amiable and easy of approach for young travelers, The airline's micro-blog content lack vitality and attraction, thus causing publicity effect to be not ideal [2]. Therefore, we should add some information that passengers pay more attention to on the basis of information input, for example, tourist spot snacks, local cheap hotel information, travel strategies, or common knowledge of flying. Reduce the stiffness, add advertising interest. At the same time, because these passengers are more active on the network, they can add interactive platform, which is helpful for airlines to further understand passengers' needs and increase publicity. Secondly, we can expand fans scale for young travelers, increase the number of fans and raise the fans' attention, and add vivid and interesting micro-blog content to attract fans' attention, carry out brand publicity and then enhance the popularity through a large scale of fans [3].

(2) Passengers who are 29 to 50 years old and travel for official purposes

Passengers who aim at official business are more pay attention to timeliness and are relatively long-term relative to the airlines. Therefore, the airlines should do good regular passenger plans for this kind of customers.

Airlines should try to collect detailed information about these passengers and set up archives, carefully analyze the passengers' travel destinations, time slot, the reactions to airlines' marketing management, and the way of booking, buying tickets and their personalized needs, so carry out the precision marketing. Because some passengers are busy with official business and can reduce unnecessary information push, flight schedules, airline arrangements and son can be sent by short message or email. The flights plan should be arranged reasonably and increase market share as much as possible, the airlines can strengthen cooperation with their companies for this part of passengers, and accumulate mileage and publish preferential information, then use passenger plan and goo service to retain customers, airlines can provide careful and precise services for passengers who often by plane, for example, can provide intimate service in late service for passengers' eating habits. Before the passengers arrive at their destination, book a hotel for them, get off the plane and get a car and save the time of these passengers. On this account the airlines improve customers' loyalty, for the original passengers already mastered by the airlines; the airlines should strengthen the communication with the passengers and further improve the service level.

(3) Passengers who are 29 to 50 years old for travel purposes

The majority of these parts of passengers are staff members, they aim at travel but their time limit is larger, so the airlines should open up boutique tourist routes for these passengers, expand civil aviation products, and continue to expand fleet scale, reasonably arrange the flight, especially for the holiday flight and route arrangement. Accordance to the traveling time, the advertisement push can be carried out in advance; it is possible to carry out publicity and promotion such as buying tickets and giving gifts. The airlines can publicize tourism guidance, tourist attractions introduction, distinctive delicacy and hotel information for these passengers in the advertisement aspect, and actively create a cooperative alliance, make the airlines' members service enjoy more convenience, such as cooperating with hotels, tourism, banks and other companies, make the passengers enjoy airlines' service and can enjoy other related services, such as accommodation, going out, catering, and other projects. According to the analysis of the high-quality tourism routes, the airline can contact the 
local hotels and cooperate, provide the passengers with the required accommodation conditions, while facilitating the passengers and improve the passengers' recognition for airlines.

(4) Passengers who are over 50 years for travel purposes

Most of these passengers belong to retired people; they have more free time and more travel opportunities, however, due to the age restriction, this part of people, they are less sensitive to online information. The airlines do not only conduct corresponding network marketing and maintain traditional television advertising for this part people, increase the creativeness of advertisements, strengthen the propaganda, and raise popularity. The airlines can open up boutique routes for these people and provide high-quality travel route analysis in product strategy. The group purchase discount policies or family ticket packages are launched; contact local hotels to strengthen cooperation, reciprocal, and purchase tickets to send hotel coupons. Due to the age of these passengers, the airlines should pay more attention to improving the services of this part of passengers, providing timely consultation and assistance, patiently guide the check-in handling and subsequent services. This part of the passengers only personally feels the airline's high-quality service, then will promote it to their friends, thus achieving the effect of word-of-mouth marketing and improve enterprise' reputation.

\section{References}

[1]. Cheng Shaoshan, Xi Jiasheng. Precision marketing-how to carry out marketing information management [M], Peking University Press, 2006, 7

[2]. Zhou Weihua, Zhou Lei. Research on influence and coping strategies of network sales to airlines[J]. Air Transport \& Business, 2008, 23 (234): 15-18.

[3]. Xie Sixin, Shi Wei. Airlines blow the new horn of market development: big strategy of network marketing[J]. Airlines, 2014 (1): 26-32. 